\title{
BMJ Open The role of environmental factors for the onset of restricted mobility outside the home among older adults with osteoarthritis: a prospective cohort study
}

\author{
Merja Rantakokko, ${ }^{1}$ Ross Wilkie ${ }^{2}$
}

To cite: Rantakokko M, Wilkie R. The role of environmental factors for the onset of restricted mobility outside the home among older adults with osteoarthritis: a prospective cohort study. BMJ Open 2017;7:e012826. doi:10.1136/ bmjopen-2016-012826

- Prepublication history and additional material for this paper are available online. To view these files please visit the journal online (http://dx.doi. org/10.1136/bmjopen-2016012826).

Received 26 May 2016 Revised 18 April 2017 Accepted 16 May 2017

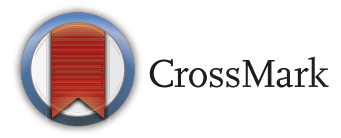

${ }^{1}$ Faculty of Sport and Health Sciences, Gerontology Research Center, University of Jyvaskyla, Jyvaskyla, Finland

${ }^{2}$ Research Institute for Primary Care Sciences, Keele University, Keele, UK

Correspondence to Dr Merja Rantakokko; merja. rantakokko@jyu.fi

\section{ABSTRACT}

Objectives The study examines how environmental factors contribute to the onset of restricted mobility outside the home among older adults with osteoarthritis.

Methods This is a prospective cohort study of adults aged 50 years and older with osteoarthritis $(n=1802)$. Logistic regression tested the association between the onset of restricted mobility outside the home and health, sociodemographic and perceived environmental barriers (hills and steep slopes, inaccessible public buildings, poor pavement condition, lack of access to public parks or sport facilities, heavy traffic or speeding cars and poor weather). The potential moderating role of environmental barriers on the association between health factors and onset was examined using interaction terms and stratified analysis. Results Of 1802 participants, $13.5 \%(n=243)$ reported the onset of restricted mobility outside the home at 3-year follow-up. Walking disability, anxiety, depression, cognitive impairment and obesity and all environmental barriers were associated with onset after adjustment for confounders. Environmental barriers had an added contribution to the effect of the health conditions on onset of restricted mobility, which was attenuated when adjusted for confounders. The added contribution remained only for walking disability and the presence of hills and steep slopes; in the presence of both, the association with onset of restricted mobility was stronger $(\mathrm{OR} 7.66,95 \% \mathrm{Cl} 4.64$ to 12.64$)$ than in the presence of walking disability (3.60, 2.43 to 5.32 ) or the presence of hills and steep slopes alone $(4.55,2.89$ to 7.16$)$.

Conclusion For older adults with osteoarthritis, environmental barriers are associated and add a contribution to that of morbidities and walking disability on the onset of restricted mobility outside the home. Awareness of environmental barriers is important when aiming to maintain mobility and activities outside the home despite health conditions in older adults.

\section{INTRODUCTION}

Mobility outside the home is important for maintenance of independence and good quality of life in old age. ${ }^{1}$ Restricted mobility outside the home is the most common form of participation restriction among older people and is associated with chronic health conditions, ${ }^{2}$ physical function, sociodemographic

\section{Strengths and limitations of this study}

A large population-based sample of older adults with osteoarthritis, identified using medical records, and high response rate.

- Longitudinal study on a topic that has not been widely studied.

- The generalisability of the study may be limited by the characteristics of the study sample; the area covered by this study is more deprived on health, education and employment, but with fewer barriers to housing and services than England as a whole.

- A potential limitation is a use of perceived environmental barriers instead of objectively assessed features.

and environmental factors. ${ }^{3}{ }^{4}$ The International Classification of Functioning, Disability and Health (ICF) highlights the role of environmental factors as barriers or facilitators of participation. ${ }^{5}$ A number of studies have shown the associations between environmental barriers, for example, poor-quality streets and long distances, with functional limitations ${ }^{6} 7$ and restricted participation among older adults, ${ }^{89}$ but have not identified why. Environmental factors may moderate the relationship between impairments, such as pain, and restricted participation; that is, the association between pain and restricted participation differs depending on the environment, for example, living in an area with lots of hills compared with living in an area that is flat. Identifying which environmental factors moderate the association between impairments and their impact is useful for directing interventions.

Older adults with osteoarthritis are especially vulnerable to environmental challenges due to physical limitation and symptoms such as pain and stiffness. ${ }^{5610}$ Osteoarthritis is the most common joint condition in adults and globally is the fastest increasing major health condition. ${ }^{11} 12$ It is a common reason for 
healthcare consultation ( 1 out of every 20 consultations to primary care in adults aged over 50 years is for osteoarthritis) and is also a common comorbidity in persons seen in primary care for other reasons. ${ }^{13}$ Previous studies have identified several health factors that are associated with poor outcomes among older adults with osteoarthritis, such as pain, multimorbidity, obesity, depression and functional limitations. ${ }^{2414}$ However, it is unclear if environmental factors moderate the impact of osteoarthritis on mobility outside the home in older adults.

In this study, we used the ICF framework ${ }^{5}$ to organise information and determine if features of the physical environmental moderate the association between health conditions and the onset of restricted mobility outside the home in older adults with osteoarthritis. Specifically, the study examines whether (1) pain, comorbidity (anxiety, depression, obesity, cognitive impairment and multimorbidity) and physical disability (ie, walking disability) at baseline are associated with an increased risk of the onset of restricted mobility outside the home at 3 years later in older adults with osteoarthritis and (2) these associations were moderated by environmental factors.

\section{METHODS}

\section{Study population}

The North Staffordshire Osteoarthritis project (NorStOP) is a population-based prospective cohort study. ${ }^{15}$ The NorStOP sampling frame comprised all individuals aged 50 years and older who were registered to receive care from one of six general practices in North Staffordshire, UK. In the UK, general practice registers offer a convenient sampling frame for population-based studies. While it is difficult to accurately state the proportion of the UK population who are registered with a general practice due to duplicate registrations of individuals and those individuals who do not register, it has been estimated that up to $98 \%$ of UK residents are registered. For this study, potential participants were those who gave written consent for medical record review and who received a diagnosis of osteoarthritis during a primary care consultation between 2000 and 2008. At baseline (2005), potential participants were mailed questionnaires and at 3-year follow-up (2008); reminders were sent at 2 and 4 weeks after the initial mailing.

Analyses for this paper included those who (1) consulted for osteoarthritis from 2000 to 2008 (the study period of NorStOP), (2) were free of restricted mobility outside the home at baseline and (3) had completed the item on mobility outside the home at 3-year follow-up $(\mathrm{n}=1802)$ (figure 1).

\section{Identification of osteoarthritis}

General practitioners in the study used the Read system to code all reasons for clinical encounters in primary care consultations. ${ }^{16}$ The Read codes cross-map to ICD-9/ ICD-10 (for diseases). Morbidity data (ie, symptoms and diseases) in this system are grouped into 18 Read chapters.
Consulted for osteoarthritis and consented for follow-up

(3068)

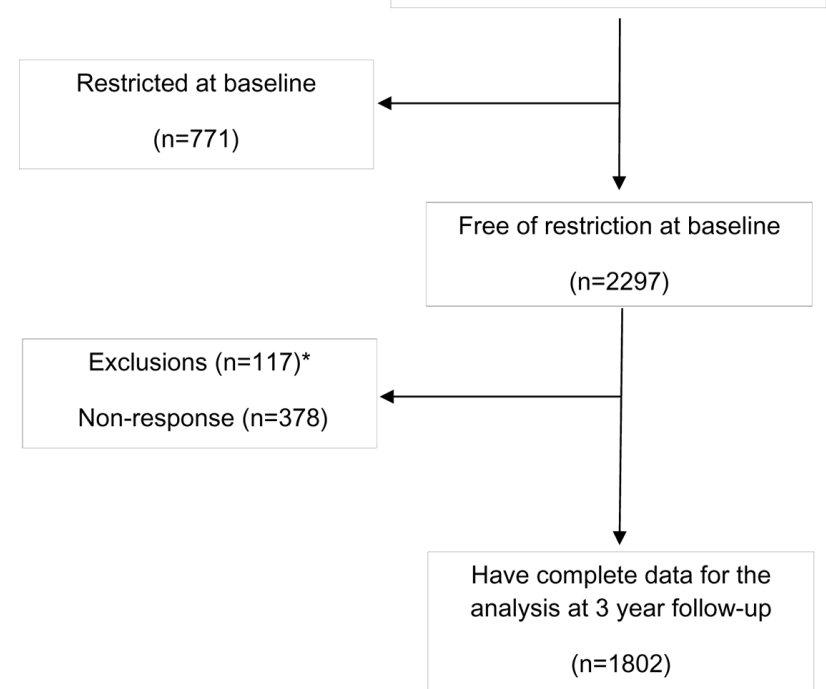

Figure 1 Flow diagram of participants. Note: *117 at baseline were excluded at 3-year follow-up having met the exclusion criteria; (1) inability to complete the questionnaire due to poor health (eg, cognitive impairment, dementia, stroke) and (2) had expressed a wish to their doctor that they did not want to participate further in research studies.

Data on these diagnostic groups were aggregated starting in 2000, continuing through the time of the follow-up questionnaire in 2008. Individuals were defined as having osteoarthritis if they had at least one consultation during this period primarily for osteoarthritis based on Read codes (N05 category) for primary care consultations. ${ }^{16}$ As osteoarthritis is a long-standing, gradually progressive chronic condition, it was assumed that a clinician-established diagnosis at any point during the study period implied that osteoarthritis was likely present at least to some degree during the entire period of observation.

\section{Measurements}

Restricted mobility outside the home was assessed with one item from the Keele Assessment of Participation (KAP) instrument. ${ }^{17} \mathrm{KAP}$ is a valid and reliable measurement tool to capture perceived participation restriction in population studies. Participants were asked whether "during the past 4 weeks, have you moved around outside your home, as and when you wanted" with response options 'all the time, most of the time, some of the time, a little of the time and none of the time'. Participants were considered to be restricted for the mobility outside the home if reported being able to move outside the home 'as and when wanted' for 'some, a little or none of the time'. Onset of restricted mobility was defined as moving from no restriction at baseline to restricted mobility at 3-year follow-up point.

All health exposures were assessed at baseline. Walking disability and bodily pain were measured using single 
items from the Short Form-36 physical functioning subscale. ${ }^{18}$ For walking disability, participants were asked whether their health limited walking more than a mile; responses were categorised to walking disability (limited a lot) and no disability (limited a little and not limited at all). For bodily pain, participants were asked "How much bodily pain have you had during the past 4 weeks?"; response options were categorised to 'none/mild' and 'moderate/severe'.

Multimorbidity was defined using general practice consultation Read code data. As defined above, a count of comorbidity from the remaining 18 Read codes was then categorised using a previously validated method, ${ }^{19}$ to identify multimorbidity (ie, $\geq 4$ morbidities).

Anxiety and depression were assessed with the Hospital Anxiety and Depression scale (HADS).${ }^{20}$ HADS is a 14 -item scale (seven items of anxiety, seven items for depression) and targets on how a person has felt in the past week. Each item is scored from 0 to 3 with total score between 0 and 21 for either anxiety or depression. Score of $8 / 21$ is identified as cut-off point for anxiety or depression ${ }^{21}$ and was used to dichotomise anxiety and depression as possible/probable case (scores 8-21) versus no case (scores 0-7). Cognitive impairment was measured using Cognitive and Alertness Behavior Subscale of Functional Limitations Profile ${ }^{22}$ and categorised into no impairment (score 0 ) and impairment (score $\geq 1$ ).

Body mass index (BMI) was calculated based on self-reported weight and height and categorised into obese $\left(\mathrm{BMI}>30 \mathrm{~kg} / \mathrm{m}^{2}\right)$ and other $\left(\mathrm{BMI}<30 \mathrm{~kg} / \mathrm{m}^{2}\right){ }^{23}$

Environmental barriers were assessed using a structured questionnaire at 3-year follow-up. Participants were asked to indicate how much they agreed or disagreed with statements related to environment barriers to moving around outside the home: live in an area with hills and steep slopes that make it difficult to move around outside (referred to as hills and steep slopes hereafter), inaccessible public buildings make it difficult to move around, poor pavement condition stops me from going out, lack of access to public parks or sport facilities stops me from going out, heavy traffic or speeding cars stop me going out and adverse weather stops me going out. The answers were on a five-point scale from 'strongly disagree' to 'strongly agree'. The items measuring environmental barriers were reliable in pilot testing (weighted kappa values for test-retest (4-week period) ranged from 0.5 (moderate) to 0.9 (almost perfect)). For the analyses, each environmental barrier was identified by responses of agree or strongly agree and compared with no barrier (neither disagree nor agree, disagree, strongly disagree).

Potential confounders included demographic factors (age, gender) and socioeconomic factors (occupational class (professional/managerial, semi-routine, routine) ) ${ }^{24}$ and educational attainment (further education or not).

\section{Statistical analyses}

Differences in distribution in health exposures, environmental barriers and potential confounders between those with and without onset of restricted mobility outside the home were tested with $\chi^{2}$ for categorical variables and t-test for continuous variables. Univariate logistic regression analyses were used to examine for the association between baseline health exposures and environmental barriers and the onset of restricted mobility outside the home at 3-year follow-up, first unadjusted then adjusted for age, gender and socioeconomic factors.

The independent effect of health and environmental factors on the onset of mobility restriction outside the home was then assessed over two stages with reference to the conceptual model of the ICF. ${ }^{5}$ In the first stage, the 'health' model was derived: all health factors were entered simultaneously into the model with age, gender and socioeconomic factors as potential confounders (model 1). In the second stage, all environmental factors were entered separately, adjusted for all health factors and confounders (models 2-7). Associations are summarised by ORs with 95\% CIs. Concordance indexes (C-statistic) were calculated to evaluate model fit. A C-statistic of 0.5 indicates that model is no better than chance in making a prediction; more than 0.7 is considered reasonable, and more than 0.8 indicates strong predictive ability. ${ }^{25}$

To examine if environmental factors moderated the association between morbidities and onset of restricted mobility outside the home, interaction terms were added to the health model separately (model 1 ). Health and environmental factors (models 2-7) significant at 5\% level were included in the interaction analysis. First, health $\times$ environmental barrier (eg, walking difficulty $\times$ hills and steep slopes) terms were included. Where there was a significant interactions (ie, $\mathrm{p}<0.05$ ), a categorical interaction variable (eg, no walking disability or hills and steep slopes, walking disability and no hills or steep slopes, no walking disability and hills and steep slopes, walking disability and steep slopes) was examined first in unadjusted and then in a fully adjusted model. Analyses were conducted with STATA 14.0 (StataCorp 2015, StataCorp LP, College Station, TX).

\section{RESULTS}

Of the 1802 participants free of participation restriction at baseline, $243(13.5 \%)$ reported onset of restricted mobility outside the home 3 years later. Onset of restricted mobility outside the home was more common among those with walking disability, severe pain, anxiety, depression, cognitive impairment, obesity and environmental barriers. There were no differences for multimorbidity $(\mathrm{p}=0.088)($ table 1$)$.

\section{Associations with onset of restricted mobility outside the home}

Following adjustment for confounders, walking disability (adjusted OR 4.5, 95\% CI 3.4 to 6.1), anxiety (OR 2.5, 95\% CI 1.9 to 3.4), depression (OR 3.4, 95\% CI 2.3 to 5.0 ), pain (OR 2.3, 95\% CI 1.8 to 3.1), cognitive impairment (OR 2.1, 95\% CI 1.6 to 2.8) and obesity (OR 2.1, 
Table 1 Characteristics of the study population at baseline overall and stratified by the onset of restricted mobility outside the home at 3-year follow-up

\begin{tabular}{|c|c|c|c|c|}
\hline & & Onset of $r$ & & \\
\hline & Total & Yes & No & \\
\hline & $\mathrm{n}=1802$ & $\mathrm{n}=243$ & $n=1559$ & p Value \\
\hline & $\%(n)$ & $\%(n)$ & $\%(n)$ & \\
\hline Walking disability & $18.2(328)$ & $46.9(114)$ & $13.7(214)$ & $<0.001$ \\
\hline Multimorbidity, $\geq 4$ & $83.5(1504)$ & $87.2(212)$ & $82.9(1292)$ & 0.088 \\
\hline Anxiety & $25.7(463)$ & $40.3(98)$ & $23.4(365)$ & $<0.001$ \\
\hline Depression & $9.3(167)$ & $19.8(48)$ & $7.6(119)$ & $<0.001$ \\
\hline Pain & & & & $<0.001$ \\
\hline None/mild & $54.8(988)$ & $36.6(89)$ & 57.7 (899) & \\
\hline Moderate/severe & $45.2(814)$ & $63.4(154)$ & $42.3(660)$ & \\
\hline Cognitive impairment & $39.7(715)$ & $57.2(139)$ & $37.0(576)$ & $<0.001$ \\
\hline BMI & & & & 0.005 \\
\hline Obese & $18.2(328)$ & $25.1(61)$ & $17.1(267)$ & \\
\hline Other & $79.4(1431)$ & $71.6(174)$ & $80.6(1257)$ & \\
\hline Unknown & $2.4(43)$ & $3.3(8)$ & $2.3(35)$ & \\
\hline Confounders & & & & \\
\hline Female & $56.4(1193)$ & $59.3(185)$ & $55.9(1008)$ & 0.270 \\
\hline Age, mean (SD) & $65.8(8.9)$ & $69.9(8.9)$ & $65.1(7.7)$ & $<0.001$ \\
\hline Occupational class & & & & 0.001 \\
\hline Managerial/professional & $23.3(493)$ & $17.6(55)$ & $24.3(438)$ & \\
\hline Semiroutine & $20.0(423)$ & $20.8(65)$ & $19.9(358)$ & \\
\hline Routine/manual & $51.8(1096)$ & $52.9(165)$ & $51.7(931)$ & \\
\hline Other & $4.8(102)$ & $8.7(27)$ & $4.2(75)$ & \\
\hline Full-time education & $15.6(281)$ & $7.8(19)$ & $16.8(262)$ & 0.001 \\
\hline Environmental barriers & & & & \\
\hline Hills and steep slopes & $12.5(226)$ & $34.6(84)$ & $9.1(142)$ & $<0.001$ \\
\hline Inaccessible public buildings & $4.1(73)$ & $12.8(31)$ & $2.7(42)$ & $<0.001$ \\
\hline Poor pavement condition & $6.4(115)$ & $16.1(39)$ & $4.9(76)$ & $<0.001$ \\
\hline Lack of access to parks & $3.4(61)$ & $9.9(24)$ & $2.4(37)$ & $<0.001$ \\
\hline Heavy traffic or speeding cars & $2.4(44)$ & $6.6(16)$ & $1.8(28)$ & $<0.001$ \\
\hline Adverse weather & 12.7 (228) & $33.7(82)$ & $9.4(146)$ & $<0.001$ \\
\hline
\end{tabular}

$95 \%$ CI 1.5 to 3.0$)$ were associated with the onset of restricted mobility outside the home. In the multivariable health model (model 1), pain was not significantly associated with onset of restricted mobility outside the home (OR 1.3, 95\% CI 0.9 to 1.8). All environmental factors were associated with onset of restriction after adjustment for confounders and all health exposures (table 2; models 2-7).

\section{Interactions}

There were significant interactions with an OR and 95\% CI less than 1.0 between hills and steep slopes that make it difficult to move outdoors and walking disability (adjusted OR $0.47,95 \%$ CI 0.24 to 0.93 ), anxiety (adjusted OR 0.45 , 95\% CI 0.22 to 0.96), depression (adjusted OR 0.25, 95\% CI 0.09 to 0.61 ) and cognitive impairment (adjusted
OR $0.46,95 \%$ CI 0.23 to 0.92$)$; between poor pavement condition and anxiety (OR $0.37,95 \%$ CI 0.15 to 0.94 ); and between heavy traffic or speeding cars and depression (OR $0.14,95 \%$ CI 0.02 to 0.88 ) (see online supplementary appendix 1).

For each of the significant interactions, in unadjusted analyses, the presence of the environmental barrier had an added contribution to the effect of the walking disability/ anxiety/depression/cognitive impairment (table 3), other than for heavy traffic and depression. The point estimate for the increased association of the joint presence attenuated with adjustment for confounders. The increased association for the presence of both health exposure and environmental factor remained only after adjustment for confounders for walking disability and the presence of hills 


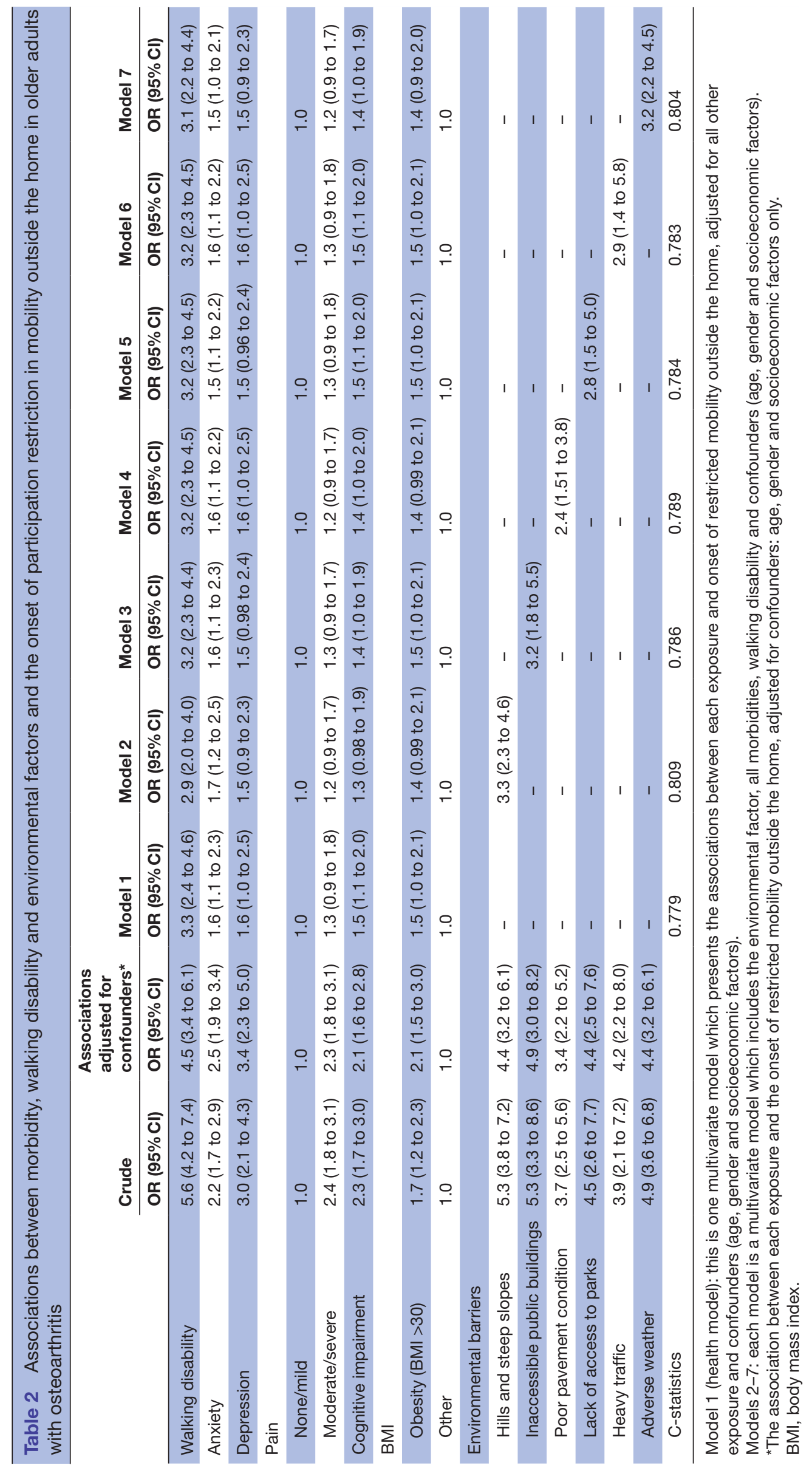


and steep slopes; the presence of both walking disability and hills and slope had a stronger association with onset of restricted mobility (adjusted OR 7.66, 95\% CI 4.64 to 12.64) than the presence of walking disability without hills and steep $(3.60,2.43$ to 5.32$)$ or the presence of steep slopes without walking disability $(4.55,2.89$ to 7.16$)$.

\section{DISCUSSION}

This study found that environmental barriers were associated with the onset of restricted mobility outside the home in older adults with osteoarthritis. In adults with osteoarthritis, the association between health conditions or walking disability and the onset of restricted mobility was greater when environmental barriers were present. This was particularly so when older adults with osteoarthritis experienced walking disability.

Our findings support the theoretical model of the ICF by providing empirical evidence of the interaction between health and environmental factors on restricted mobility. Our findings also give support to previous studies that have emphasised importance of using comprehensive models of mobility including physical,

Table 3 Associations between morbidity, walking disability and environmental factors, included as an interaction term, and the onset of participation restriction in mobility outside the home in older adults with osteoarthritis

\begin{tabular}{lll}
$\begin{array}{l}\text { Frequency of the onset } \\
\text { of restricted mobility } \\
\text { outside the home at } \\
\text { 3-year follow-up }\end{array}$ & Crude & $\begin{array}{l}\text { Associations } \\
\text { adjusted for } \\
\text { confounders* }\end{array}$ \\
\hline & OR $(95 \% \mathrm{Cl})$ & $\begin{array}{l}\text { Adjusted OR } \\
(95 \% \mathrm{Cl})\end{array}$
\end{tabular}

Walking disability and hills and steep slopes No walking disability, no hills and steep slopes Walking disability, no hills and steep slopes

$6.8 \quad 1$

No walking disability, hills and steep slopes 29.3 5.71 (4.00 to 8.13$)$ 3.60 (2.43 to 5.32$)$ Walking disability, and hills and steep slopes 29.2

5.69 (3.69 to 8.78$)$
4.55 (2.89 to 7.16$)$

Anxiety and hills and steep slopes

\begin{tabular}{|c|c|c|c|}
\hline No anxiety, no hills and steep slopes & 7.5 & 1 & 1 \\
\hline Anxiety no hills and steep slopes & 17.9 & $2.71(1.93$ to 3.79$)$ & $2.09(1.40$ to 3.11$)$ \\
\hline No anxiety, hills and step slopes & 35.9 & $6.93(4.69$ to 10.24$)$ & 4.21 (2.76 to 6.43$)$ \\
\hline Anxiety, and hills and steep slopes & 40.3 & 8.38 (4.91 to 14.29$)$ & $4.04(2.16$ to 7.55$)$ \\
\hline \multicolumn{4}{|l|}{ Depression and hills and steep slopes } \\
\hline No depression, no hills and steep slopes & 8.6 & 1 & 1 \\
\hline Depression, no hills and steep slopes & 26.2 & $3.74(2.43$ to 5.77$)$ & 2.18 (1.32 to 3.62$)$ \\
\hline No depression, hills and step slopes & 37.0 & 6.22 (4.39 to 8.80$)$ & $4.14(2.83$ to 6.06$)$ \\
\hline Depression, and hills and steep slopes & 37.8 & $6.43(3.22$ to 12.82$)$ & $2.22(1.03$ to 4.78$)$ \\
\hline
\end{tabular}

Cognitive impairment and hills and steep slopes

\begin{tabular}{|c|c|c|c|}
\hline No cognitive impairment, no hills and steep slopes & 7.0 & 1 & 1 \\
\hline Cognitive impairment, no hills and steep slopes & 15.3 & 2.40 (1.72 to 3.34$)$ & 1.64 (1.14 to 2.37$)$ \\
\hline No cognitive impairment, hills and step slopes & 35.0 & $7.16(4.44$ to 11.56$)$ & 5.01 (3.00 to 8.38$)$ \\
\hline Cognitive impairment, and hills and steep slopes & 38.9 & $8.47(5.49$ to 13.06$)$ & 3.81 (2.35 to 6.19$)$ \\
\hline \multicolumn{4}{|l|}{ Anxiety and poor pavement condition } \\
\hline No anxiety, no poor pavements & 9.5 & 1 & 1 \\
\hline Anxiety, no poor pavements & 19.8 & 2.34 (1.72 to 3.18$)$ & 1.76 (1.21 to 2.55$)$ \\
\hline No anxiety, poor pavements & 33.8 & $4.84(2.86$ to 8.19$)$ & 3.55 (2.01 to 6.27$)$ \\
\hline Anxiety, and difficult pavements & 34.1 & 4.90 (2.56 to 9.40$)$ & 2.31 (1.09 to 4.90$)$ \\
\hline
\end{tabular}

Depression and heavy traffic

\begin{tabular}{llll} 
No depression, no heavy traffic & 11.3 & 1 & 1 \\
Depression, no heavy traffic & 28.9 & $3.19(2.19$ to 4.65$)$ & $1.75(1.11$ to 2.76$)$ \\
No depression, heavy traffic & 38.9 & $4.99(2.50$ to 9.92$)$ & $4.25(2.01$ to 8.99$)$ \\
\hline Depression, and heavy traffic & 25.0 & $2.61(0.52$ to 13.04$)$ & $1.01(0.18$ to 5.53$)$ \\
\hline
\end{tabular}

*Adjusted for all morbidities, walking disability, age, gender and socioeconomic factors. 
psychosocial and environmental determinants. ${ }^{26}{ }^{27}$ It is possible that certain health conditions that lead to walking disability increase risk of onset of participation restriction in demanding environments because the environment no longer supports the level of functional capacity. ${ }^{10}$ While previous cross-sectional studies have shown the association between environmental characteristics and participation in out-of-home activities ${ }^{9}$ and an interaction between environmental characteristics (eg, heavy traffic) and health for participating in voting, obtaining healthcare and interpersonal interaction, ${ }^{28}$ our study goes beyond previous literature by identifying how environmental factors contribute to the onset of restricted mobility and link with common consequences or comorbidities in people with osteoarthritis.

In this study, the most common environmental barriers were hills and steep slopes and adverse weather. Hills and steep slopes increase requirements for physical capability and are a particular barrier for older adults with osteoarthritis. People with difficulties in walking report more and different environmental barriers that affect their participation in community activities than those without difficulty. ${ }^{28}$ This suggests that the interaction between person and the environment and the balance between these two (ie, person-environment fit) ${ }^{10}$ is influential to whether a person is able to move outdoors. People may compensate for their impairments, ${ }^{29}$ for example, by stopping to rest when moving outdoors or use assistive devices, but environmental barriers may make these compensations more difficult to perform, exacerbating the situation. For example, people with walking disability may be concerned for their safety when moving outdoors because of heavy traffic and speeding cars, especially when crossing the street. ${ }^{30}$ People with depression or cognitive impairment may not encounter these barriers because they participate less or change how they participate to compensate for their impairment. ${ }^{31}$

Adverse weather is a common barrier for outdoor mobility among older adults, and snow, ice and rainfall increase the risk of participation restriction. ${ }^{32}$ For example, icy conditions may increase difficulty to maintain balance leading to fear of falling despite of the health, thus restricting possibilities to participate in outdoor activities. ${ }^{33}$ In this study, adverse weather was associated with onset, but there were no interactions with comorbidity or physical disability.

Older people most often go outdoors for the purposes of shopping, running daily errands and walking for exercise. ${ }^{34}$ If public buildings for shopping or running daily errands are inaccessible, it may restrict possibilities for using these community amenities. Parks and green areas form important spaces for exercise and motivate people to go out. ${ }^{35-37}$ Poor access to these resources may be decisive when considering participation in outdoor activities, especially for people with osteoarthritis. ${ }^{38}$ The considerable prevalence of osteoarthritis indicates that this is an issue which impacts on a large number of adults in the population.
The lack of significant interactions between some health conditions and environmental barriers suggests that some barriers have a similar impact whether a health condition/disability is present or absent (eg, the adjusted OR for walking disability if access to parks is absent is 3.23; $95 \%$ CI 2.28 to 4.58 ) and 2.83 (0.80 to 10.03 ) when present; interaction $3.23 / 2.83=0.88$ (0.91 (0.28 to 2.98) when adjusted (see online supplementary appendix 1$)$ ). This may be because people can compensate for a barrier; for example, poor access to parks can be compensated by access to other outdoor facilities. It may also suggest that the impact of some barriers is dependent on the health condition or the presence of disability (eg, there is only a significant interaction with heavy traffic in people who are depressed and not with any other condition or physical disability).

\section{Strengths and limitations}

The study has a number of strengths. The analysis was performed with a large population-based sample of older adults with osteoarthritis, identified using medical records. The response rate was high and was comparable to other population surveys. The sample size was sufficient to identify interactions; the sample size of 1802 had $98.6 \%$ power at the 0.05 significance level to identify an interaction between walking disability and hills and steep slopes. The available data covered a number of important factors in relation to the onset of mobility outside the home for older adults with osteoarthritis. The instruments used to identify restricted mobility outside the home, the symptoms of osteoarthritis and comorbidity have been validated for use in population studies of older adults. ${ }^{17182122}$

Study limitations were as follows: restricted mobility outside the home was measured by self-report and focused on person-perceived participation. This is the most appropriate method for capturing an individual's social participation; however, it is susceptible to measurement error, and it may not take account of frequency of outdoor mobility. Responders who do not mobilise outdoors may report restricted mobility but not environmental barriers that they will not experience which may lead to underestimation of associations. Perceived environmental barriers were included in this analysis as they more appropriately capture the presence of environmental barriers that an individual encounters when mobilising outdoors. While objective measures identify environmental features (eg, population density, existence of hills), individuals may not perceive these or experience them as barriers to mobility. Perceived environmental barriers may be a more valid indicator than objectively measured neighbourhood features when studying restricted mobility outside the home. There may be other predictors and confounders which may be important but were not included in this study. For example, performance-based measures, such as gait speed, can be used as clinical marker of decline in participation. ${ }^{39}$ Since performance and especially gait patterns may also be influenced by environmental 
features ${ }^{40}$ the combined association between these in relation to participation may form an interesting target for future research. The generalisability of the study may be limited by the characteristics of the study sample; the area covered by this study is more deprived on health, education and employment, but with fewer barriers to housing and services than England as a whole. As in most prospective studies, there was some loss to follow-up and missing data; those who dropped out of the analysis were more likely to be female $(\mathrm{p}=0.010)$ and have depression $(\mathrm{p}=0.046)$, anxiety $(\mathrm{p}<0.001)$ and walking disability $(\mathrm{p}=0.001)$ than those included the sample. There were no differences for pain $(p=0.060)$, obesity $(p=0.650)$, cognitive impairment $(\mathrm{p}=0.106)$ or multimorbidity $(\mathrm{p}=0.281)$. Data on outdoor mobility were measured 3 years apart, and restriction in mobility may vary during this period; we could not measure variation between the 3-year time points. There may also be changes in exposure status during the follow-up period which are not accounted for in the analysis. However, this is expected to be small; for example, $93 \%$ of those who were not depressed at baseline were not depressed at follow-up. In addition, we do not have information on possible relocation during the follow-up period; this may be a reason for the onset of restricted mobility outside the home, although with the mailing procedure used for this survey suggests that this will be small. Those who did not consent to medical record review were unhealthier at baseline; however, the effect of this on the association between the exposures and restricted mobility is unknown.

\section{Conclusion}

The findings of this study suggest that some environmental barriers have an important role in preventing older adults with osteoarthritis mobilising outside their home, particularly when impairments and walking disability are present. To prevent the onset of restricted mobility outside the home for older adults with osteoarthritis, both clinical and non-clinical approaches are required. Clinical approaches aimed at reducing pain, anxiety, depression and walking disability will be useful, but consideration of an individual's environment is important. Identifying older adults with osteoarthritis who live in more challenging environments can lead to a targeted approach to overcoming such barriers, within a rehabilitation programme. Approaches to reducing environmental barriers and community planning, such as improving access to public buildings, increasing mobility friendly environments where low physical and mental capacities do not prevent mobility and function and the provision of public transport may prevent restricted mobility, improve social participation and support active ageing.

Contributors MR and RW designed the research questions, plan of analyses and statistical analyses and interpreted the results and drafted the manuscript. MR is the main author of the manuscript.

Funding NorSt0p project was supportedby theMedical Research Council, UK (grant numbers G9900220 and G0501798) and by theNorth Staffordshire Primary Care
R\&D Consortium. MR was supported by the Academy of Finland (grant number 285747) and Finnish Ministry of Education and Culture. The study sponsors had no role in the study design; in the collection, analysis and interpretation of the data; in the writing of the report; or in the decision to submit the paper for publication.

Competing interests None declared.

Patient consent Obtained.

Ethics approval The North Staffordshire Local Research Ethics Committee granted approval, and all participants gave written consent to participate.

Provenance and peer review Not commissioned; externally peer reviewed.

Data sharing statement The Research Institute for Primary Care and Health Sciences, Keele University, has established data sharing arrangements to support joint publications and other research collaborations. Applications for access to anonymised data from our research databases are reviewed by the Centre's Data Custodian and Academic Proposal Committee, and a decision regarding access to the data is made subject to the NRES ethical approval first provided for the study and to new analysis being proposed. Further information on our data sharing procedures can be found on the centre's website () or by emailing the centre's data manager (data-sharing-pcs@keele.ac.uk).

Open Access This is an Open Access article distributed in accordance with the Creative Commons Attribution Non Commercial (CC BY-NC 4.0) license, which permits others to distribute, remix, adapt, build upon this work non-commercially, and license their derivative works on different terms, provided the original work is properly cited and the use is non-commercial. See: http://creativecommons.org/ licenses/by-nc/4.0/

(c) Article author(s) (or their employer(s) unless otherwise stated in the text of the article) 2017. All rights reserved. No commercial use is permitted unless otherwise expressly granted.

\section{REFERENCES}

1. Rantakokko M, Portegijs E, Viljanen A, et al. Changes in life-space mobility and quality of life among community-dwelling older people: a 2-year follow-up study. Qual Life Res 2016;25:1189-97.

2. Wilkie R, Peat G, Thomas E, et al. Factors associated with participation restriction in community-dwelling adults aged 50 years and over. Qual Life Res 2007;16:1147-56.

3. Rantakokko M, Mänty M, Rantanen T. Mobility decline in old age. Exerc Sport Sci Rev 2013;41:19-25.

4. Wilkie R, Peat G, Thomas E, et al. Factors associated with restricted mobility outside the home in community-dwelling adults ages fifty years and older with knee pain: an example of use of the International classification of functioning to investigate participation restriction. Arthritis Rheum 2007;57:1381-9.

5. World Health Organization (WHO). International classification of functioning, disability and Health: ICF. Geneva: World Health Organization, 2001.

6. Keysor JJ, Jette AM, LaValley MP, et al. Community environmental factors are associated with disability in older adults with functional limitations: the MOST study. J Gerontol A Biol Sci Med Sci 2010;65:393-9.

7. Rantakokko M, Iwarsson S, Mänty M, et al. Perceived barriers in the outdoor environment and development of walking difficulties in older people. Age Ageing 2012;41:118-21.

8. Richard L, Gauvin L, Gosselin C, et al. Staying connected: neighbourhood correlates of social participation among older adults living in an urban environment in Montréal, Quebec. Health Promot Int 2009;24:46-57.

9. Hand C. Associations between neighbourhood characteristics and community mobility in older adults with chronic health conditions. Disabil Rehabil 2016;38:1-8.

10. Lawton MP, Nahemow L. Ecology and aging process. In: Eisdorfer C, Lawton MP, eds. The psychology of adult development and aging. Washington DC: American Psychological Association, 1973:619-74.

11. Murray CJ, Vos T, Lozano R, et al. Disability-adjusted life years (DALYs) for 291 diseases and injuries in 21 regions, 1990-2010: a systematic analysis for the global burden of disease study 2010 . Lancet 2012;380:2197-223.

12. Mody GM, Brooks PM. Improving musculoskeletal health: global issues. Best Pract Res Clin Rheumatol 2012;26:237-49.

13. Jordan K, Clarke AM, Symmons DP, et al. Measuring disease prevalence: a comparison of musculoskeletal disease using four general practice consultation databases. $\mathrm{Br} J$ Gen Pract 2007;57:7-14. 
14. Sharif B, Garner R, Sanmartin C, et al. Risk of work loss due to illness or disability in patients with osteoarthritis: a population-based cohort study. Rheumatology 2016;55:861-8.

15. Thomas E, Wilkie R, Peat G, et al. The North Staffordshire Osteoarthritis Project--NorStOP: prospective, 3-year study of the epidemiology and management of clinical osteoarthritis in a general population of older adults. BMC Musculoskelet Disord 2004;5:2.

16. NHS Information. The clinical terms version 3 (the READ codes). Birmingham: NHS Information Authority, 2000.

17. Wilkie R, Peat G, Thomas E, et al. The Keele Assessment of Participation: a new instrument to measure participation restriction in population studies. combined qualitative and quantitative examination of its psychometric properties. Qual Life Res 2005;14:1889-99.

18. Ware JE, Sherbourne CD. The MOS 36-item short-form health survey (SF-36). I. Conceptual framework and item selection. Med Care 1992;30:473-83.

19. Kadam UT, Croft PR; North Staffordshire GP Consortium Group. Clinical multimorbidity and physical function in older adults: a record and health status linkage study in general practice. Fam Pract 2007;24:412-9.

20. Zigmond AS, Snaith RP. The hospital anxiety and depression scale. Acta Psychiatr Scand 1983;67:361-70.

21. Bjelland I, Dahl AA, Haug TT, et al. The validity of the Hospital Anxiety and Depression Scale. An updated literature review. J Psychosom Res 2002;52:69-77.

22. Bergner M, Bobbitt RA, Carter WB, et al. The Sickness Impact Profile: development and final revision of a health status measure. Med Care 1981;19:787-805.

23. Department of Health. Health Survey for England. London: The Stationary Office, 19991999.

24. Office for National Statistics. Standard Occupational classification. vol 2. the coding index. London: The office for National Statistics, 2000.

25. Hosmer DW, Lemeshow S. Applied Logistic regression. New York: John Wiley \& sons, 2000.

26. Umstattd Meyer MR, Janke MC, Beaujean AA. Predictors of older adults' personal and community mobility: using a comprehensive theoretical mobility framework. Gerontologist 2014;54:398-408.

27. Webber SC, Porter MM, Menec VH. Mobility in older adults: a comprehensive framework. Gerontologist 2010;50:443-50.
28. Clarke PJ, Ailshire JA, Nieuwenhuijsen ER, et al. Participation among adults with disability: the role of the urban environment. Soc Sci Med 2011;72:1674-84.

29. Gignac MA, Cott C, Badley EM. Adaptation to disability: applying selective optimization with compensation to the behaviors of older adults with osteoarthritis. Psychol Aging 2002;17:520-4.

30. Rosenberg DE, Huang DL, Simonovich SD, et al. Outdoor built environment barriers and facilitators to activity among midlife and older adults with mobility disabilities. Gerontologist 2013;53:268-79.

31. Shumway-Cook A, Patla A, Stewart A, et al. Environmental components of mobility disability in community-living older persons. J Am Geriatr Soc 2003;51:393-8.

32. Clarke PJ, Yan T, Keusch F, et al. The impact of weather on mobility and participation in older U.S. adults. Am J Public Health 2015;105:1489-94.

33. Deshpande N, Metter EJ, Lauretani F, et al. Activity restriction induced by fear of falling and objective and subjective measures of physical function: a prospective cohort study. J Am Geriatr Soc 2008;56:615-20.

34. Tsai LT, Rantakokko M, Viljanen A, et al. Associations between reasons to go outdoors and objectively-measured walking activity in various life-space areas among older people. J Aging Phys Act 2016;24:85-91.

35. Lee AC, Maheswaran R. The health benefits of urban green spaces: a review of the evidence. J Public Health 2011;33:212-22.

36. Rantakokko M, Iwarsson S, Portegijs E, et al. Associations between environmental characteristics and life-space mobility in communitydwelling older people. J Aging Health 2015;27:606-21.

37. Li F, Fisher KJ, Brownson RC, et al. Multilevel modelling of built environment characteristics related to neighbourhood walking activity in older adults. J Epidemiol Community Health 2005;59:558-64.

38. van der Pas S, Schaap LA, Castell MV, et al. Availability and use of neighborhood resources by older people with osteoarthritis: results from the European Project on OSteoArthritis. Health Place 2016;37:1-7.

39. Fairhall N, Sherrington C, Cameron ID, et al. Predicting participation restriction in community-dwelling older men: the Concord Health and Ageing in Men Project. Age Ageing 2014;43:31-7.

40. Marigold DS, Patla AE. Age-related changes in gait for multi-surface terrain. Gait Posture 2008;27:689-96. 